\title{
Quadro clínico do transtorno obsessivo-compulsivo
}

\author{
Albina R Torres e Sumaia I Smaira
}

Departamento de Neurologia e Psiquiatria da Faculdade de Medicina de Botucatu - Unesp. Botucatu, SP, Brasil

\begin{abstract}
Obsessive-compulsive disorder is a very heterogeneous condition, not always easy to be identified. Obsessions are intrusive thoughts, impulses or images that cause anxiety or other emotional discomfort, whereas compulsions are repetitive behaviors or mental acts voluntarily performed to counterbalance or minimize the discomfort, or magically prevent any feared events. The most common symptoms are contamination, aggressive, somatic and sexual obsessions and washing, checking, repeating, counting and ordering compulsions. Patients usually have multiple symptoms simultaneously, which often change over time. Although the insight is typically preserved, it varies among patients and also fluctuates in the same patient in different ocasions. The main features are: exacerbated appraisal of risks, pathological doubts and incompleteness, as well as excessive sense of responsibility and guilt and thought/action fusion. As patients frequently feel ashamed of their symptoms, they can be reticent about them. Consequently, it usually takes time till they get adequate treatment.
\end{abstract}

Keywords Obsessive-compulsive disorder. Diagnosis. Clinical features. Obsessions.

\section{Definição de sintomas e apresentação geral}

A descrição clínica e o diagnóstico do transtorno obsessivo-compulsivo (TOC) são mais complexos do que se pode supor, em função de alguns aspectos que serão expostos brevemente neste trabalho.

A caracterização do transtorno baseia-se na ocorrência primária de obsessões e/ou compulsões. Obsessões são pensamentos, impulsos ou imagens mentais recorrentes, intrusivos e desagradáveis, reconhecidos como próprios e que causam ansiedade ou mal-estar relevantes ao indivíduo, tomam tempo e interferem negativamente em suas atividades e/ou relacionamentos. Note-se que imagens aversivas e impulsos egodistônicos ameaçadores, em geral agressivos, podem predominar. Já compulsões são comportamentos ou atos mentais repetitivos que o indivíduo é levado a executar voluntariamente em resposta a uma obsessão ou de acordo com regras rígidas, para reduzir a ansiedade/mal-estar ou prevenir algum evento temido. ${ }^{1}$ Assim, enquanto as obsessões causam desconforto emocional, os rituais compulsivos (sempre excessivos, irracionais ou mágicos) tendem a aliviá-lo, mas não são prazerosos. Já em 1935, Lewis ${ }^{2}$ afirmava: "quanto mais agradável um ato repetitivo, menos provável que seja compulsivo". A função de neutralização ou atenuação imediata da ansiedade manteria os sintomas em um ciclo de difícil rompimento ${ }^{3} \mathrm{em}$ que, paradoxalmente, para sentir-se melhor, o indivíduo se escraviza.

Apesar de mais freqüente, nem sempre obsessões e compulsões estão associadas, havendo pacientes puramente obsessivos e, mais raramente, só compulsivos. ${ }^{4-7}$ No último caso, os rituais (p. ex.: de colecionamento, simetria ou ordenação) são executados para aliviar um mal-estar descrito como ansiedade, sensação de premência, imperfeição ou incompletude, sem uma preocupação ou temor específicos relacionados ao comportamento. As ações são repetidas até que a pessoa se sinta melhor ou considere que aquilo está "certo" ("just right”) ou concluído.

Um aspecto característico é a fácil evocabilidade dos sintomas, havendo infindáveis estímulos externos (sujeira, bactérias, facas) e internos (pensamentos, lembranças) capazes de, por associação, desencadear desconforto. Estes podem se generalizar também pelo plano simbólico (p. ex.: pensamentos sexuais ou agressivos e sujeira). ${ }^{3} \mathrm{O}$ medo é idiossincrático: enquanto um considera "sujo" sangue e tudo que se refere a isso, outros temem contato com urina, gordura, graxa, pó de café, vidro etc.

Na maioria dos casos, há múltiplas obsessões e compulsões simultâneas e não sintomas únicos ou pares, e os pacientes mudam de tema ou tipo de sintoma com o passar do tempo. Trata-se em regra de um quadro crônico e freqüentemente de início precoce,${ }^{6,8}$ com flutuação na intensidade dos sintomas ao longo do tempo.

Enquanto na maior parte dos casos há piora em fases de vida difíceis, alguns relatam atenuação dos sintomas na ocorrência de algum problema sério que exija enfrentamento. ${ }^{2}$ Não há necessariamente piora progressiva, mas os rituais tendem a ficar mais sedimentados com o tempo. Ressalte-se que a gravidade é bastante variável, havendo desde casos leves até aqueles extremamente graves e incapacitantes, 


\section{Tabela - "Spectrum" de subtipos de TOC (Rasmussen \& Eisen ${ }^{5,12}$ ).}

Preocupações com

contaminação

Responsabilidade

patológica
Obsessões sexuais e
agressivas

Dúvida patológica
Necessidade de ordem

e simetria
Ritualizadores

puros mesmo para atividades rotineiras (veja neste volume artigo de Miranda \& Bordin sobre curso clínico).

\section{Tipos de sintomas}

O conteúdo dos pensamentos ou das imagens mentais aversivas geralmente se refere a acidentes, doenças ou perda de pessoas queridas. As obsessões de contaminação (Aids, sujeira, radioatividade) são conhecidas, e as somáticas (preocupações com outras doenças, com a aparência física) podem apresentar pior nível de crítica. ${ }^{7}$ As obsessões agressivas apresentam-se geralmente como "fobias de impulsos": medo de ferir, matar ou prejudicar alguém sem querer, de se matar, fazer algo proibido ou embaraçoso (p. ex.: furtar, xingar, assediar). Muitos evitam manusear facas, tesouras, fósforos, ou quaisquer objetos que considerem perigosos, ou ficar sozinhos, por não confiarem em si mesmos. Mesmo nada de fato ocorrendo, a ameaça persiste e costuma ser muito assustadora, por vezes associada à dúvida sobre ter ou não feito o ato tão temido. Pensamentos obsessivos "neutros" são palavras, sons, músicas intrusivas ou imagens que, pela recorrência, atrapalham e tornam-se aversivos.

As compulsões de verificação podem estar relacionadas a obsessões somáticas (auto-exame) e ao medo de, por imprudência, vir a causar alguma catástrofe. Os rituais de lavagem (de mãos, banhos, objetos), quando intensos, causam até dermatites e problemas de coluna. As compulsões de contagem podem se associar às de repetição e são geralmente mentais (somas e divisões desnecessárias, repetir várias vezes tal ato), e as de simetria são inúmeras: posição de livros, de sapatos ou outros objetos, ordenação de roupas no varal e mesmo simetria em toques ou esbarrões (p. ex.: ter de tocar com a mão direita naquilo que foi tocado com a esquerda ou vice-versa). Já os rituais de colecionamento são menos conhecidos: incapacidade de se desfazer de jornais, notas fiscais antigas, embalagens inúteis, papéis de bala ou objetos encontrados na rua. São considerados rituais "diversos": sapatear, rezar, perguntar, relembrar, gesticular, tocar, cuspir etc. Como se vê, trata-se de um transtorno extremamente heterogêneo, ${ }^{9}$ que pode ter incontáveis apresentações; ou seja, em princípio, qualquer comportamento pode ser compulsivo. ${ }^{7}$

Alguns autores ${ }^{4,5}$ consideram as obsessões de contaminação como as mais comuns. Dúvidas patológicas costumam se associar aos rituais de conferência e são também bastante freqüentes. Entre os pacientes de Rasmussen \& Tsuang, ${ }^{6} 80 \%$ apresentavam compulsões de verificação, consideradas como os sintomas mais comuns. No Brasil, Del Porto ${ }^{10}$ avaliou 105 pacientes e encontrou principalmente obsessões de agressividade (52\%), contaminação (44\%) e somáticas (40\%), compulsões de limpeza (57\%) e verificação (56\%).

Estudando a variação sintomatológica em quase 300 casos,
Leckman et $\mathrm{al}^{9}$ agruparam sintomas que tendem a co-ocorrer e propuseram a existência de quatro fatores principais, responsáveis por mais de $60 \%$ da variação clínica: obsessões - principalmente agressivas e somáticas - e verificação (fator I); simetria e ordenação, também envolvendo repetição e contagem (fator II); contaminação e limpeza (fator III); e colecionamento (fator IV).

Um sintoma raro e menos conhecido é a lentidão obsessiva, em que os pacientes não repetem suas ações, mas demoram horas em tarefas diárias. Na maioria, há indecisão, ruminações e rituais encobertos provavelmente responsáveis pela lentidão. Aparentemente temeriam errar ou causar problemas, por isso a demora excessiva nas ações. ${ }^{11}$

\section{Características centrais}

Para Rasmussen \& Eisen, ${ }^{5,12}$ dentro da grande diversidade fenomenológica do TOC, três características seriam básicas: avaliação exagerada de riscos, dúvida patológica e sensação de incompletude (Tabela).

Os obsessivos vivenciam exageradamente quaisquer riscos. A ansiedade seria mais intensa quando predominasse essa sensação exacerbada de vulnerabilidade ao perigo. No extremo oposto, estariam pacientes com rituais de simetria/ordenação ou lentidão, com predominância da sensação de não-finalização e menos ansiedade.

A dúvida patológica consiste na incapacidade de se certificar, por exemplo, de que a porta está trancada, o botijão desligado, a louça bem lavada ou, mais irracional e incompreensivelmente, de que não engoliram cacos de vidro, não são homossexuais, não traíram o cônjuge ou mataram alguém sem perceber. Vale lembrar que o TOC já foi conhecido como "loucura da dúvida" ("folie de doute"). Na verdade, em muitos casos tal separação é difícil, com os três aspectos muito interligados.

Segundo Pitman, ${ }^{13}$ o problema central seria a persistência de "sinais de erro", que não desapareceriam com o comportamento, mantendo a sensação de dúvida e incompletude. Enquanto o sinal perceptual não coincidir com o referencial interno, as compulsões se repetiriam para tentar reduzir essa diferença ("mismatch"), mas em vão, pois o dano estaria no sistema comparador.

A culpa é outro fenômeno importante e constante nas descrições clínicas, considerada a base do sofrimento desses pacientes. ${ }^{14}$ Para Lima,${ }^{15}$ o peso insuportável da culpa (sujeira moral) é essencial, junto com a dúvida, as fobias e a sombra da morte. Segundo descreve, haveria dois subgrupos principais: pacientes mais voltados para um passado de culpa, que temem principalmente a responsabilidade, e outros mais preocupados com o futuro ameaçador, predominando a sensação de fragilidade (mais temores de contaminação e da morte). Enquanto estes se sentem ameaçados, aqueles se consideram uma ameaça para os outros. 
Tallis ${ }^{14}$ enfatiza a fusão psicológica entre pensamento e ação: como temem que pensar algo ruim resulte na realização do pensamento, tendem a suprimir a raiva ou sua expressão para evitar "fatalidades". Os limites entre mundo mental e real estariam de certa forma comprometidos. Tal natureza bizarra do pensamento obsessivo teria dado ao TOC sempre um "status especial" entre os transtornos de ansiedade.

\section{Julgamento crítico}

A maioria dos pacientes apresenta a capacidade crítica preservada e envergonha-se de seus pensamentos e/ou comportamentos, procurando ocultá-los. Muitos, enquanto conseguem, restringem seus rituais a alguns cômodos da casa ou a quando estão sozinhos. Assim, mesmo pessoas bem próximas podem desconhecer a existência do problema.

Trata-se, portanto, de uma doença em geral secreta, que pode levar anos até ser diagnosticada e tratada. Por isso, a importância de investigar diretamente na anamnese a ocorrência de obsessões e compulsões que, mesmo assim, podem só ser admitidas pelo paciente quando o vínculo terapêutico estiver fortalecido. Alguns só procuram ajuda em fases de piora (p. ex: incapacitação, medo de perder o autocontrole sobre os impulsos) ou por complicações, como depressão secundária. ${ }^{6-8}$

Entretanto, há pacientes ambivalentes ao considerar os sintomas absurdos, e alguns até acreditam e temem as conseqüências. Insel \& Akiskal $^{16}$ relataram que $17 \%$ dos casos que estudaram acreditavam parcialmente nas obsessões e eram mais refratários ao tratamento. Portanto, em casos mais graves ou em fases de agravamento, pode ocorrer prejuízo da crítica, com os sintomas não se apresentando como obsessões típicas (caráter egodistônico), e sim como idéias prevalentes ou até delirantes (egossintônicas). Essa apresentação menos usual é denominada no DSM-IV 1 de "TOC com poor insight" (para mais detalhes, vide artigo de Hounie et al neste volume).
Entre 90 pacientes avaliados por Okasha et al, ${ }^{17}$ nenhum apresentava crítica excelente, havia comprometimento leve em $26 \%$, moderado em $50 \%$, grave em $14 \%$ e total em $9 \%$. Assim, possivelmente é mais adequada uma concepção dimensional de graus de crítica e não categorial (com ou sem "insight”). De toda forma, mesmo não sendo tão simples, a questão egodistonicidade versus egossintonicidade, como postulou Bleuler ao dizer que enquanto os obsessivos lutam contra a idéia os paranóides lutam pela idéia, normalmente na existência obsessiva é a parte saudável que detém a identidade, vivenciando como absurdos os significados atribuídos pela parte doentia. ${ }^{18}$

\section{Critérios diagnósticos}

Enquanto a CID-10 19 categoriza o TOC junto aos "transtornos neuróticos, relacionados ao estresse e somatoformes", mas separadamente dos transtornos ansiosos e fóbicos, o DSM-IV ${ }^{1}$ classifica-o entre os transtornos de ansiedade. Isto já aponta uma controvérsia quanto à importância da ansiedade nesse transtorno, considerado por alguns mais próximo aos transtornos de humor ou de pensamento.

\section{Conclusões}

O TOC é um quadro em geral secreto, que apresenta uma fenomenologia rica e diversificada, com infinitas possibilidades de apresentação, o que pode dificultar sua identificação. Envolve sempre medos descabidos, dúvidas insolúveis e comportamentos repetidos na busca de um alívio sempre fugaz. $\mathrm{O}$ grau de crítica pode variar entre os pacientes e no mesmo indivíduo conforme a ocasião. Implica, em geral, grande sofrimento e costuma ser subdiagnosticado e subtratado.

Por fim, vale ressaltar que mesmo quando as apresentações clínicas são semelhantes, cada paciente reage ao problema conforme o contexto sociofamiliar e suas características de personalidade, aspectos que devem ser sempre considerados no manejo de cada caso particular. ${ }^{20}$

\section{Referências}

1. American Psychiatric Association. Diagnostic and statistical manual of mental disorders- DSM-IV. 4th ed. 1994.

2. Lewis A. Problems of obsessional illness. Proc R Soc Med 1936;29:13-27.

3. Baer L, Minichiello WE. Behavior therapy for obsessivecompulsive disorder. In: Jenike MA, Baer L, Minichiello WE, editors. Obsessive-compulsive disorders: theory and manegement. Chicago: Year Book Medical Publishers; 1986. p. 45-75.

4. Jenike MA, Baer L, Minichello WE. Obsessive-compulsive disorder: theory and management. Chicago: Year Book Medical Publishers; 1986.

5. Rasmussen SA, Eisen JL. Epidemilogy, clinical features and genetics of obsessive-compulsive disorder. In: Jenike MA, Asberg M, editors. Understanding obsessive-compulsive disorder. Toronto: Hogrefe \& Huber Publishers; 1991.

6. Rasmussen SA, Tsuang MT. Clinical characteristics and family history in DSM-III obsessive compulsive disorder. Am J Psychiatry 1986;143:317-22.
7. Torres AR, Smaira SI. Características clínicas do distúrbio obsessivo-compulsivo: estudo de 45 casos. Rev ABP-APAL 1993;15:44-50.

8. Goodwin DW, Guze SB, Robins E. Follow-up studies in obsessional neurosis. Arch Gen Psychiatry 1969;20:182-7.

9. Leckman JF, Grice DE, Boardman J, Zhang H, Vitale A, Bondi C et al. Symptoms of obsessive-compulsive disorder. Am J Psychiatry 1997;154:911-7.

10. Del Porto JA. Distúrbio obsessivo-compulsivo: fenomenologia clínica de 105 pacientes e estudo de aspectos trans-históricos e transculturais [Tese livre-docência]. São Paulo: Escola Paulista de Medicina; 1994. p. 170.

11. Ratnasuriya RH, Marks IM, Forshaw DM, Hymas NFS. Obsessive slowness revisited. Brit J Psychiatry 1991;159:273-4.

12. Rasmussen SA, Eisen JL. The epidemiology and differential diagnosis of obsessive-compulsive disorder. J Clin Psychiatry 1994;55(supl 10):5-10. 
13. Pitman RK. A cybernetic model of obsessive-compulsive psychopathology. Compr Psychiatry 1987;28:334-43.

14. Tallis F. Obsessions, responsability and guilt: two case reports suggesting a common and specific aetiology. Beh Res Ther 1994;32:143-5.

15. Lima MA. Responsabilidade e fragilidade: contribuição ao estudo da psicopatologia fenomenológica do transtorno obsessivocompulsivo [dissertação de mestrado]. São Paulo: Faculdade de Medicina da Universidade de São Paulo; 1994. p. 157.

16. Insel TR, Akiskal HS. Obsessive-compulsive disorder with psychotic features: a phenomenologic analysis. Am J Psychiatry 1986;143:1527-33.
17. Okasha A, Saad A, Khalil AK, Dawla AS, Yehia N. Phenomenology of obsessive-compulsive disorder: a transcultural study. Compr Psychiatry 1994;35:191-7.

18. Ballerini A, Stanghellini G. Phenomenological questions about obsessions and delusions. Psychopathol 1989;22:315-9.

19. Organização Mundial de Saúde. Classificação de transtornos mentais e de comportamento da CID-10: descrições clínicas e diretrizes diagnósticas. Porto Alegre: Artes Médicas; 1993.

20. Torres AR, Del Porto JA. Comorbidity of obsessive-compulsive disorder and personality disorders: a Brazilian controlled study. Psychopothol 1995;28:322-9.

\section{Correspondência: Albina Rodrigues Torres}

Departamento de Neurologia e Psiquiatria - Faculdade de Medicina de Botucatu (FMB) - Unesp - Distrito de Rubião Jr. 18.618-970 Botucatu, SP

Tel.: (0xx14) 6802-6260-Fax: (0xx14)6821-5965-E-mail: atorres@fmb.unesp.br 